\title{
A IMPORTÂNCIA DO APRENDIZADO FORA DA SALA DE AULA
}

DOI: 10.37702/2175-957X.COBENGE.2021.3533

Luiz Felipe Pfleger - luizfelipepfleger@gmail.com

Universidade Federal de Santa Catarina

Rua Osvaldo de Souza S/N

88135-028 - Palhoça - SC

André Luís Kirsten - kirsten.andre@ufsc.br

Universidade Federal de Santa Catarina

Rua João Pio Duarte Silva 1536

88037-001 - Florianópolis - SC

André Duarte - andreduarte.eel@gmail.com

Universidade Federal de Santa Catarina

Rua 1

11111-111 - São José - SC

Davi Grumiche Seemann - daviseemann@gmail.com

Universidade Federal de Santa Catarina

Rua joão carvalho 101

88025-010 - Florianópolis - SC

Gustavo Grubler de Souza - gustavogrubler27@gmail.com

Universidade Federal de Santa Catarina

Rua Pedro João Pereira 1020

88904-150 - Araranguá - SC

Isabela Souza Oliveira - isaoliveira1999@gmail.com

Universidade Federal de Santa Catarina

Rodovia Amaro Antônio Vieira 2593

88034-102 - Florianópolis - SC

Julia Capistrano Nunes da Silva - jcapistranonunes@gmail.com

Universidade Federal de Santa Catarina

Rua Vidal Gregório Pereira 524

88095-030 - Florianópolis - SC

Lorenzo Claudino dos Santos Borges - Iorenzocsborges@gmail.com 
Universidade Federal de Santa Catarina

Rua Jair Hamms 241

88137-084 - Palhoça - SC

Miguel Boing - miguel-boing@hotmail.com

Universidade Federal de Santa Catarina

Av Ivo Silveira 17

88475-000 - Anitápolis - SC

Ricardo Pereira - ricardopereira.eel@gmail.com

Universidade Federal de Santa Catarina

Rua Alcino Navegantes Moreira 203

88134-100 - Palhoça - SC

Victor João Lourenço - victor.j.lourenco@gmail.com

Universidade Federal de Santa Catarina

Rua Ana Maria Nunes 275

88037-020 - Florianópolis - SC

Vitória Beatriz Bianchin - vitoriabbianchin@gmail.com

Universidade Federal de Santa Catarina

Rua João Batista Meneguzzi 165

89778-000 - Arvoredo - SC

Resumo: Com um mercado de trabalho cada vez mais competitivo, o evento Volta ao Mundo do Conhecimento surgiu como uma forma de suprir a deficiência de conhecimentos gerais sobre engenharia através de visitas técnicas em empresas ao redor do Brasil. O seu planejamento e execução é feito pelo PET EEL com um ano de antecedência onde seus membros devem, através de grupos de trabalhos definidos, contatar empresas, agendar datas, divulgar o evento, entre outros, exigindo portanto alta organização por parte do grupo. Ao final de cada uma das viagens técnicas são enviados aos participantes formulários com perguntas relacionadas às suas experiências durante a viagem e a relevância do evento a sua formação acadêmica. As respostas deste formulário mostram resultados positivos de graduandos que sentiram que a VMC trouxe uma ótima assimilação dos conceitos teóricos vistos em sala de aula com os práticos.

Palavras-chave: Visita técnica. PET. VMC. Extensão. Graduação. 


\section{A IMPORTÂNCIA DO APRENDIZADO FORA DA SALA DE AULA}

\section{INTRODUÇÃO}

Os métodos de ensino sofreram muitas mudanças ao longo dos anos, sempre se adequando a realidade que se encontravam. No momento atual, o ensino superior surge como uma forma de preparação do graduando para o mercado de trabalho. Nos cursos de graduação, são aplicadas aulas teóricas e práticas para a formação do profissional. Entretanto, dentro das universidades nem sempre é possível ter uma visão do funcionamento de empresas. Além disso, o mercado está cada vez mais exigente, e conhecimentos práticos ganham cada vez mais importância para alcançar pré-requisitos necessários no mercado de trabalho. Em um curso de engenharia, é muito clara a distinção entre a visão acadêmica e a empresarial. Sendo assim, torna-se necessário o contato com empresas para adquirir conhecimentos práticos, ampliar a rede de contatos e expandir seus horizontes além da teoria.

Uma metodologia existente para assimilação prática de conteúdos são as viagens técnicas. De acordo com o engenheiro mecânico Carlos Monezi (2005), da Universidade Presbiteriana Mackenzie, ela permite ao aluno o contato com a aplicação prática dos conteúdos aprendidos em sala de aula. Ademais, segundo o pesquisador norte-americano David Paul Ausubel (1968), a aprendizagem é um processo que envolve a interação da nova informação abordada com a estrutura cognitiva do aluno. Assim, as visitas técnicas são importantes para complementar os conhecimentos dos estudantes adquiridos em sala de aula.

Para promover a realização dessas visitas, o Programa de Educação Tutorial da Engenharia Elétrica da UFSC (PET EEL) realiza anualmente a Volta ao Mundo do Conhecimento (VMC), uma viagem de visitas técnicas cujo objetivo é conhecer empresas voltadas ao setor de engenharia. Esse programa, assim como as instituições de ensino superior (IES), trabalha com três pilares: pesquisa, ensino e extensão. Esse último pilar consiste em ações realizadas junto à comunidade que possibilitam o compartilhamento do conhecimento adquirido por meio do ensino e da pesquisa desenvolvidos na instituição. Dessa forma, a realização da VMC é essencial para o desenvolvimento da extensão dentro do grupo juntamente com a Universidade e a comunidade acadêmica.

A VMC visa incentivar os alunos a uma graduação de excelência por meio do contato com as necessidades e habilidades requeridas pelas empresas em questão, tornando possível conhecer o dia a dia de um engenheiro na indústria, o que agrega conhecimentos que outrora seriam inalcançáveis na graduação por si só.

Esse evento é aberto para os graduandos de engenharias, com destaque aos alunos do curso de Engenharia Elétrica. Todo ano, é escolhido um destino diferente para a viagem, na qual são visitadas empresas da região escolhida, proporcionando uma variedade de áreas para visitas, bem como uma oportunidade de conhecer diferentes regiões do país, com as suas particularidades sociais, culturais e econômicas. Além disso, busca-se um custo acessível para que todos os interessados consigam participar.

\section{PLANEJAMENTO E REALIZAÇÃO DA VIAGEM TÉCNICA}

A VMC é realizada na metade do ano, porém seu planejamento é iniciado ao final do ano precedente a ela, através de uma reunião entre os integrantes do PET EEL para avaliar qual será o próximo destino, seguindo as condições de viabilidade de custos do evento, variabilidade de destinos e avaliando o feedback realizado na VMC anterior. Após a escolha 
do destino principal, é feita uma busca de interesses por empresas da região, selecionando em geral aquelas que são de grande porte, e abrangendo diversos ramos do mercado.

Depois de uma pré-seleção de empresas, os membros do grupo de trabalho (GT) de Extensão e Eventos, um dos constituintes do PET EEL, são responsáveis por entrar em contato com as organizações escolhidas, apresentando a proposta para uma possível visita. Dessa forma, os integrantes do PET têm a oportunidade de desenvolver responsabilidade e melhorar a eficiência do trabalho em equipe. É necessário uma comunicação clara entre todos os membros do grupo, para que todos fiquem cientes das visitas agendadas. Além disso, é responsabilidade do coordenador do GT de Extensão e Eventos definir uma data e um cronograma da viagem, visando um melhor aproveitamento do destino. Também é realizada uma seleção de hotéis a fim de se escolher o melhor custo benefício.

Toda essa organização da VMC é responsabilidade do grupo todo, contudo cabe ao coordenador de Extensão e Eventos uma delegação de atividades, sendo imprescindível uma ótima comunicação com os coordenadores do financeiro e de marketing do grupo.

Além disso, uma das principais tarefas para a realização da viagem é conseguir o meio de transporte. Os membros do PET devem procurar apoio por meio da pró-reitoria de assuntos estudantis (PRAE) e do centro tecnológico da universidade. É necessário alguns documentos e insistência por parte do grupo, demonstrando a importância da viagem de visitas técnicas.

Ao grupo de trabalho de Marketing é destinado a responsabilidade de toda a divulgação da viagem aos graduandos. As redes sociais são utilizadas no intuito de alcançar mais estudantes, além de ser um meio simples e fácil de manusear, sendo possível informar as datas abertas para inscrição, o destino, as empresas que serão visitadas, o itinerário e tudo que for necessário.

Ao GT de Tesouraria cabe a responsabilidade de cuidar de toda a parte financeira da viagem, determinar os custos e os valores do ingresso com o melhor custo, de forma que a viagem seja acessível a maior parte da graduação.

Durante a realização da VMC, o professor tutor do PET acompanha os graduandos nas visitas técnicas, para auxiliar tanto na organização do evento, quanto na supervisão da atividade.

Ao final de cada viagem, é feito um formulário de forma opcional aos participantes, como forma de buscar os pontos que devem ser melhorados para as próximas viagens, quanto aos pontos que devem ser mantidos. Tais pontos podem ser tanto a parte organizacional do evento, qualidade, bem como destinos visitados e sugestões.

Dessa forma, nota-se que a VMC é um evento de grande porte e de grande responsabilidade para todos do grupo. Assim, é imprescindível uma ótima organização e acompanhamento pelo coordenador do GT de Eventos e Extensão para que o evento saia como o esperado.

\section{METODOLOGIA DE AVALIAÇÃO DA VIAGEM}

A Volta ao Mundo do Conhecimento é uma forma de desenvolver no estudante interesse de ser um sujeito questionador e mais motivado com o curso escolhido. Muito se aprende na faculdade, porém sente-se a falta do contato com as indústrias para conhecer melhor o mercado de trabalho. Assim, toda a VMC é elaborada pensando no aluno de engenharia e como essa viagem pode ter um impacto positivo para o aprendizado destes.

Para tornar a VMC um evento cada vez mais assertivo é necessário um contato com alunos que participaram de viagens passadas. Dessa forma, feedbacks de participantes são fundamentais para o aperfeiçoamento e continuação desse projeto. Com o objetivo de 
avaliar a VMC, foi elaborado um formulário online, e enviado a graduandos participantes das edições passadas.

A construção do formulário foi baseada na construção de eixos principais abordados, e a partir deles foram feitas algumas perguntas objetivas para avaliar o desempenho em tal quesito. Os temas escolhidos para o questionário foram sobre conhecimentos técnicos e práticos, assimilação de conteúdos, visão sobre o mercado de trabalho, contato com empresas e ambientes profissionais e conhecimentos gerais sobre cada área da engenharia. As perguntas foram feitas em formato objetivo, para poder quantificar melhor o desempenho de cada quesito. Além disto, foi elaborada uma questão dissertativa, cujo foco era um relato sobre as mudanças de perspectiva sobre engenharia depois da participação na VMC.

Outro enfoque que deve ser considerado para obter uma avaliação mais precisa é analisar a importância das visitas técnicas sobre o ponto de vista do professor. Para isso, entrevistamos o professor André Luís Kirsten, doutor em engenharia elétrica e atual tutor do PET EEL. Da mesma forma que o formulário, foram levantados os principais eixos para avaliação, e elaboradas perguntas baseadas neles. Os temas escolhidos para a entrevista foram sobre os aprendizados técnicos, visita técnica e teoria, suas diferenças entre o estágio, ambientes de trabalho e impacto de visitas técnicas para o futuro engenheiro.

\section{RESULTADOS OBTIDOS}

O gráfico 1 apresenta as respostas obtidas dos alunos participantes de antigas VMCs quanto a importância de visitas técnicas, e mostra em uma escala de 0 a 10 as notas dadas por eles. 
A partir da tabela é notável que os alunos por experiência própria acreditam que as viagens de visitas técnicas são muito importantes.

Ademais, algumas falas de graduandos também mostram como a visita pode auxiliar o enriquecimento do saber de diferentes formas:

"Estamos acostumados a lidar com a parte teórica do saber relacionado à engenharia. Tal domínio representa uma parcela muito importante do conhecimento como um todo, pois permite o entendimento profundo de tudo que serve como alicerce na engenharia. Contudo, o contato com o mundo real (prático) e com as aplicações da teoria é muito ausente na maior parte do ensino brasileiro em engenharia. Por esse motivo, iniciativas como a VMC são tão valiosas. Pessoalmente, tive a oportunidade de observar a real função que um engenheiro desempenha, seja em uma empresa, seja na sociedade no geral, o que abriu uma nova gama de possibilidades. Por consequência, tal experiência me proporcionou uma mudança de pensamento e atitude, no sentido de buscar conhecimentos além da sala de aula, que me permitissem estar preparado para o mercado de trabalho."

"Ajudou a compreender que a engenharia vai além da parte puramente técnica no mercado. Temos oportunidades também em aspectos de gestão, planejamento, vendas e aplicação de diversas outras soft skills que complementam a profissão e representam diferencial."

Quanto à assimilação de conceitos vistos durante a graduação, foi perguntado para antigos participantes das VMCs, e de acordo com as respostas obtidas, mostrada no gráfico 2 , está claro que de alguma forma, elas contribuíram para este quesito.

\section{Gráfico 2 - Contribuição da VMC para assimilação de conceitos vistos na graduação.}

\section{A VMC contribuiu para assimilação de conteúdos vistos durante a graduação? 14 respostas}

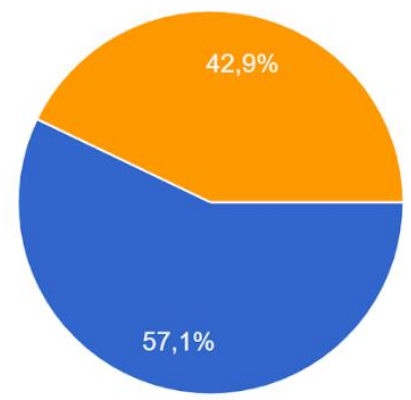

Fonte: Desenvolvido pelos autores.

Outra forma de analisar o impacto de viagens como essas é questionar professores. Por isso, entrevistamos o professor André Luís Kirsten. Segue abaixo sua visão em relação a importância da visita técnica: 
"As visitas técnicas são muito importantes, pois incentivam os alunos a quererem aprender as disciplinas da graduação, intrigam interesse pelas disciplinas, além de tornar possível o melhor entendimento de como os aprendizados obtidos na graduação são aplicados na prática. Além do mais, quando o aluno vê o funcionamento na prática, desperta nele interesse em aprender mais sobre o assunto."

\title{
5 CONCLUSÃO
}

A Volta ao Mundo do Conhecimento foi criada com o intuito de auxiliar e completar a graduação de futuros engenheiros. Esse artigo abordou métodos e resultados obtidos na avaliação da importância dessas visitas para os estudantes. Através do formulário aplicado e da entrevista com o tutor do grupo alguns pontos positivos foram notados.

Em relação a importância das visitas e a contribuição destas na assimilação de conceitos teóricos aprendidos na universidade é perceptível que os alunos que participaram percebem essas qualidades atribuídas a viagens técnicas. Além disso, as visitas têm um impacto muito grande na visão dos estudantes frente a possibilidade de futuros empregos para engenheiros. Por ser uma formação tão ampla, é muito importante esse contato com diferentes áreas, desde a parte de gestão até a mais técnica. Dessa forma, o aluno estará ciente da gama de possibilidades e ficará mais motivado se identificando com alguma área.

A entrevista com o tutor também foi essencial para analisar a visão dos professores frente a realização de visitas técnicas. Como foi percebido na fala dele, essas viagens despertam interesse nos alunos e ajudam no entendimento de conceitos teóricos. Tal consequência é essencial aos estudantes, estar motivado ao curso muitas vezes é difícil devido a carga de responsabilidades, dessa forma essas visitas possibilitam um estímulo de energias.

Em suma, a VMC tem um impacto muito positivo para os estudantes de engenharia e deve ser continuada e aperfeiçoada para impactar cada vez mais os graduandos.

\section{Agradecimentos}

Agradecemos aos outros integrantes e ao tutor do PET-EEL pelo apoio, aos participantes e colaboradores da VMC e por fim a MEC pelo financiamento da bolsa concedida aos membros.

\section{REFERÊNCIAS}

AUSUBEL, D.P. Educational psychology. A cognitive view. 2. ed. New York: Holt, Rinehart \& Wiston, 1968.

MONEZI, Carlos A.; A visita técnica como recurso metodológico aplicado ao curso de engenharia. In: XXXIII Congresso Brasileiro de Ensino de Engenharia, 2005, Campina Grande. Anais. Campina Grande.

\section{THE IMPORTANCE OF LEARNING OUTSIDE THE CLASSROOM}

\begin{abstract}
With an increasingly competitive job market, the Volta ao Mundo do Conhecimento event emerged as a way to fill the deficiency of general engineering knowledge through technical visits in companies around Brazil. Its planning and execution is done by PET EEL one year in advance where its members must, through defined work


groups, contact companies, schedule dates, publicize the event, among others, thus requiring high organization by the group. At the end of each of the technical trips, participants are sent forms with questions related to their experiences during the trip and the relevance of the event to their academic background. The responses on this form show positive results from undergraduates who felt that VMC brought a great assimilation of the theoretical concepts seen in the classroom with the practical ones.

Keywords: Technical Visit. PET. VMC. Extension. Graduation. 